\title{
Chemical Compound Classification by Elemental Signatures in Castle Dust Using SEM Automated X-ray Particle Analysis
}

Diana L. Ortiz-Montalvo ${ }^{1}$, Edward P. Vicenzi ${ }^{1,2}$, Nicholas W. Ritchie ${ }^{1}$, Carol A. Grissom ${ }^{2}$, Richard A. Livingston ${ }^{3}$, Zoe Weldon-Yochim ${ }^{4}$, Joseph M. Conny ${ }^{1}$ and Scott A. Wight ${ }^{1}$.

${ }^{1}$ National Institute of Standards and Technology, Gaithersburg, MD, USA.

${ }^{2}$ Museum Conservation Institute, Smithsonian Institution, Suitland, MD, USA.

${ }^{3}$ Department of Materials Science \& Engineering, University of Maryland, College Park, MD, USA.

${ }^{4}$ Department of Art History, University of Delaware, Newark, DE, USA.

Discoloration on the Smithsonian Institution Building (1847-1855) and Enid A. Haupt Garden gateposts (1987) was recently revealed to be related to a Mn enriched rock varnish [1]. Mn does not appear to be derived locally from the building stone; therefore, its source is likely related to atmospheric dust transport. Minor oxygen isotopic ratios $\left(\delta^{17} \mathrm{O}\right)$ of sulfate in desert varnish demonstrate that atmospheric deposition of dust is an important component of the varnish formation process [2]. A 2017 study of architectural rock varnish determined that vehicle emissions are a likely source of Mn [3]. In this study, we evaluate airborne dust as a potential Mn source at a location where rock varnish is actively forming.

Urban dust samples were collected on polycarbonate filters using a portable sampler (Hi-Q Environmental Products, Model PSU-2-GN) [4] with a size selective inlet (10 $\mu \mathrm{m}$ particle diameter size cut-off, URG). The collection times were 24 hours, and the volumetric flow rate was $30 \mathrm{~L} / \mathrm{min}$. Samples were collected near the Haupt Garden gateposts and heavily trafficked Independence Ave. (Fig. 1). A TESCAN MIRA3 and a $20 \mathrm{keV} / 1 \mathrm{nA}$ electron beam and $4 \times 30 \mathrm{~mm}^{2}$ PulseTor silicon drift detectors (SDD) were used to analyze particles. Automated analysis was performed using the SEMantics extension to NIST DTSA-II [5]. The sum of the 4 SDD spectra (dwell time of 400 ms per spectrum) were used for quantification using NIST Graf [6]. A novel algorithm was then used to cluster the data obtained for 39,491 particles [7]. Data were then reprocessed using a manually developed rule set.

Table 1 lists the major particle classes representing $\approx 92 \%$ of the particle population. Figure 2 shows representative elemental signatures of the four major particle classes: silicate, Fe oxide, vehicle-related and $\mathrm{CaMg}$ carbonate. Only 52 out of $\approx 40 \mathrm{~K}$ particles had elevated levels of $\mathrm{Mn}(\geq 10 \mathrm{wt} \%)$. Overall, our results show low, but detectable levels of $\mathrm{Mn}$ in the atmosphere in the Castle area. Efforts are underway to estimate the mass of Mn transported by atmospheric dust deposition for particles under 10 $\mu \mathrm{m}$ in size. To our knowledge, this is the first study to examine the linkage between individual particle analysis of dust and active rock varnish formation.

\section{References:}

[1] Vicenzi, E.P. et al, Heritage Science 4 (2016), 26.

[2] Bao, H., Michalski, G.M. and Thiemens, M.H, Geochimica et Cosmochimica Acta 65 (2000), 2029.

[3] Macholdt, D.S. et al, Atmospheric Environment 171 (2017) 205.

[4] Any mention of commercial products is for information only; it does not imply recommendation or endorsement by NIST.

[5] Ritchie, N.W.M. and Filip, V., Microscopy and Microanalysis Proceedings 17(S2) (2011), 896.

[6] Lindstrom, A.P. and Ritchie, N.W., Microscopy and Microanalysis Proceedings 20(S3) (2014), 748. 
[7] Ritchie, N.W., Microscopy and Microanalysis 21(5) (2015), 1173.

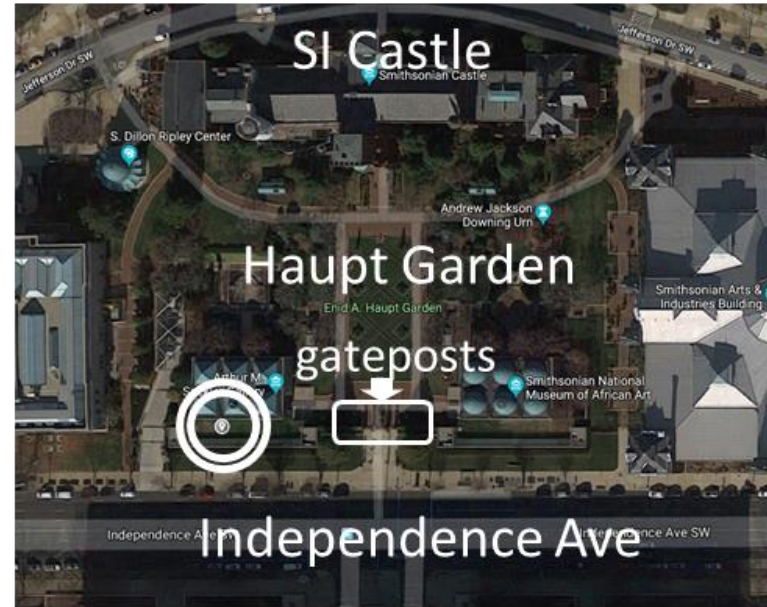

Table 1. Major particle classes ranked by count fraction of 39,491 particles. ( $\approx 92 \%$ of particle population)

Figure 1. Plan view of the Smithsonian Institution Building (SI Castle), Enid A. Haupt Garden gateposts (white rectangle), Independence SW Ave., and dust collection site (nested white circles) in Washington, DC, USA.

\begin{tabular}{|cccc}
\hline Rank & Class name & Count & Fraction (\%) \\
\hline 1 & silicate & 16,868 & 40.7 \\
\hline 2 & Fe oxide & 10,141 & 25.7 \\
\hline 3 & vehicle-related & 2,455 & 6.2 \\
\hline 4 & CaMg carbonate & 1,912 & 4.8 \\
\hline 5 & Fe(Mn) oxide & 1,341 & 3.4 \\
\hline 6 & Ca carbonate & 1,287 & 3.3 \\
\hline 7 & Fe oxide + silicate & 1,192 & 3.0 \\
\hline 8 & Ca sulfate & 970 & 2.5 \\
\hline 9 & Fe sulfide & 760 & 1.9 \\
\hline
\end{tabular}

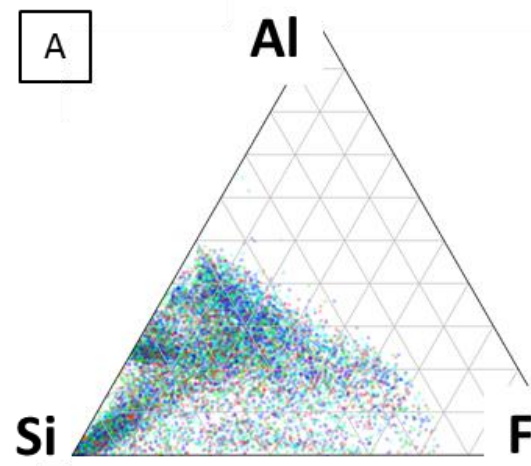

silicate

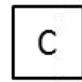

$\mathrm{Fe}$

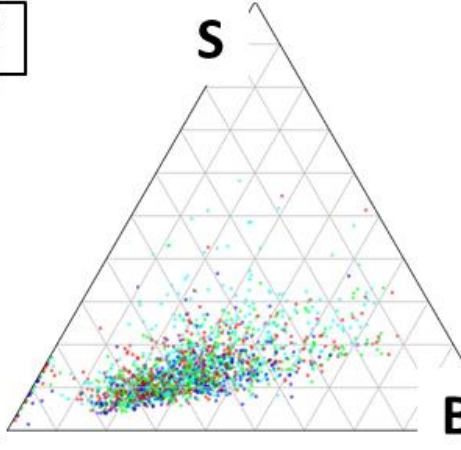

vehicle-related

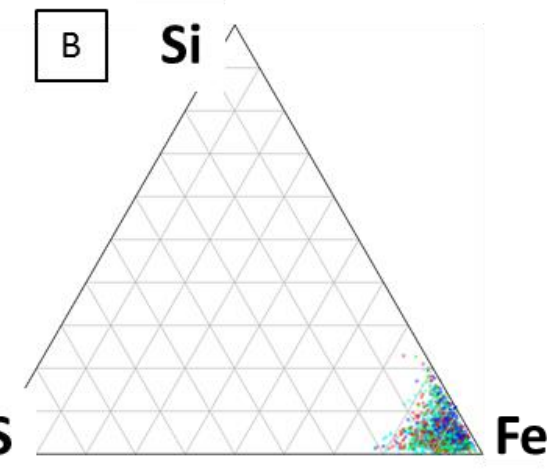

Fe oxide

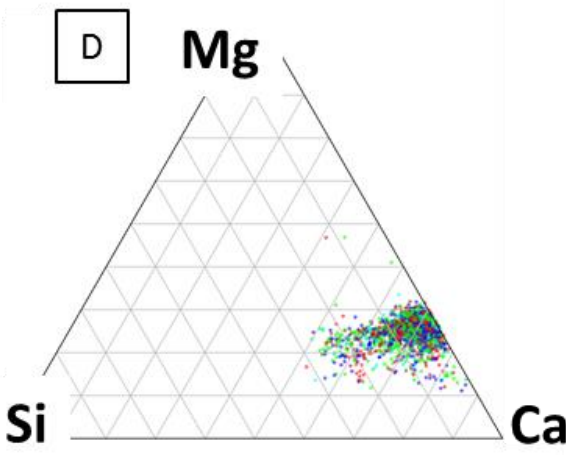

CaMg carbonate

Figure 2. Elemental signatures for major particle classes by weight fraction of ternary end-members.

A) silicate. B) $\mathrm{Fe}$ oxide. C) vehicle-related (Fe-Ba-S-Cu-Si-Sb-Zr). and D) CaMg carbonate. 